\title{
Tonometry to assess the adequacy of splanchnic oxygenation in the critically ill patient
}

\author{
J. Arnold, J. Hendriks, C. Ince, H. Bruining
}

Surgical Intensive Care Unit, Academic Hospital Rotterdam, Dr. Molewaterplein 40, NL-3015 GD Rotterdam, The Netherlands

Received: 11 March 1993/Accepted: 16 November 1993

\begin{abstract}
Tonometry, a relatively non-invasive technique for indirectly measuring the intramucosal $\mathrm{pH}(\mathrm{pHi})$ of the gastrointestinal tract, has recently been developed for use in critically ill patients. Reports in the literature suggest that the technique is of greatest benefit to patients at risk of developing reductions in splanchnic oxygenation (decreased $\mathrm{O}_{2}$ delivery) in whom early detection of the ischemic episode could possibly guide treatment. Tonometry, although still at a relatively early stage in its clinical development, could be of value for selected patient groups although further evaluation of the technique is necessary.
\end{abstract}

Key words: Intramucosal $\mathrm{pH}-$ Intraluminal $\mathrm{PCO}_{2}-$ Intestinal ischemia - Tissue acidosis - Intensive care monitoring

Adequate tissue oxygenation is one of the main therapeutic goals in the severely ill patient. In critical illness, oxygen delivery to the tissues $\left(\mathrm{DO}_{2}\right)$ my fall below a critical value and $\mathrm{O}_{2}$ extraction cannot increase sufficiently leading to a decrease in oxygen consumption $\left(\mathrm{VO}_{2}\right)$ of the tissues [1, 2, 3]. As $\dot{\mathrm{VO}}_{2}$ becomes dependent on $\mathrm{DO}_{2}$, anaerobic metabolism may become more significant in the $\mathrm{O}_{2}$ deprived cells. If the cellular hypoxia is sufficiently severe and prolonged the ensuing acidosis can lead to marked derangements in cellular metabolism resulting ultimately in cell death.

Illness and accidental injury generally stimulate the release of endogenous vasoconstrictors, such as vasopressin and angiotensin II, that provoke a selective redistribution of the cardiac output $[4,5]$. The splanchnic vascular bed appears to be particularly susceptible to the actions of vasoconstrictors [6]. Thus blood flow to the splanchnic tissues is frequently reduced and redirected to other vital organs such as the brain, heart and kidneys. Inade-

Correspondence to: J. Arnold quately oxygenated, the splanchnic tissues may become prone to ischemia-related complications. There is recent literature on patients with burns suggesting that if the integrity of the intestinal mucosa becomes compromised, as in severe ischemia, translocation of enteric bacteria and endotoxins from the lumen of the gut may occur and give rise to systemic septicemia $[7,8]$.

The clinical need for monitoring the adequacy of tissue oxygenation has led to a variety of assessment techniques. Measurements of cardiac output and the partial pressures of $\mathrm{O}_{2}\left(\mathrm{PO}_{2}\right)$ and $\mathrm{CO}_{2}\left(\mathrm{PCO}_{2}\right)$ in arterial and venous blood samples are used frequently in intensive care patients to calculate whole body $\dot{\mathrm{DO}}_{2}$ and $\mathrm{VO}_{2}$. Serum lactate concentrations also provide information regarding whole body oxygenation. However, during severe illness, $\dot{\mathrm{DO}}_{2}$ and $\dot{\mathrm{VO}}_{2}$ are unlikely to be altered uniformly in different tissue beds. Although perfusion of peripheral tissues can be evaluated by measurement of skin temperature, capillary refill time and more recently, laser Doppler assessment of skin (cutaneous) blood flow, these methods yield little or no information regarding the oxygenation of individual vital organs whose dysfunction could have a significant influence on patient outcome $[9,10]$.

Imaging techniques, such as infrared spectroscopy and nuclear magnetic resonance, can provide information concerning the oxygenation of individual tissues. A number of factors, including technical problems and cost, preclude their routine clinical application. Oxygenation and oxygen uptake in vital organs could be assessed by measuring blood flow and arterio-venous differences across these organs, a technique requiring invasive cannulation. Another means of assessing tissue oxygenation is determining organ-specific, extra-cellular interstitial $\mathrm{pH}$ since inadequate tissue oxygenation is manifest by increasing reliance on anaerobic metabolism with a concomitant rise in the lactate and hydrogen ion $\left(\mathrm{H}^{+}\right)$concentration. While the implantation of $\mathrm{pH}$ probes into vital organs is too invasive for routine clinical monitoring, a much less invasive technique, tonometry, has recently been developed for determining intramucosal $\mathrm{pH}(\mathrm{pHi})$ of hollow organs, especially the gastrointestinal tract $[11-13]$. 
Since the splanchnic circulation is one of the first to be reduced in critical illness, it has been proposed that gastrointestinal pHi can be used clinically as an early sign of inadequate tissue oxygenation, enabling the clinician to initiate appropriate resuscitative treatment (e.g. fluid therapy, inotropic support) at an earlier stage, with a potential advantage over delayed intervention [14].

\section{Tonometry - principles and technique}

A gastric or sigmoid tonometer is a gas-impermeable sampling tube to which a gas-permeable silicone balloon has been attached distally (Fig. 1). The naso-gastric tonometer has an additional lumen that serves as a gastric sump drain. Once in situ, the balloon is filled with physiologic saline. An equilibration period of at least $10 \mathrm{~min}$ is then required for the $\mathrm{PCO}_{2}$ of the saline to equilibrate with the $\mathrm{PCO}_{2}$ of the gastrointestinal lumen. The diffusion of $\mathrm{CO}_{2}$ occurs freely across the membranes of cells in the superficial layers of the gastrointestinal tract and thus an equilibrium is established with the intraluminal fluid, as well as with the saline in the tonometer balloon [11-15]. After the $\mathrm{PCO}_{2}$ has equilibrated, a sample of saline is aspirated from the tonometer and its $\mathrm{PCO}_{2}$ determined with a conventional blood-gas analyser. The $\mathrm{PCO}_{2}$ is corrected by a factor that is dependent on the equilibration time. A sample of arterial blood is drawn concomitantly and its bicarbonate $\left(\mathrm{HCO}_{3}^{-}\right)$concentration determined using conventional blood gas analysis. It is assumed that the $\mathrm{HCO}_{3}^{-}$concentration in the intracellular fluid of the mucosal tissue is in equilibrium with the $\mathrm{HCO}_{3}^{-}$concentration in the mucosal capillary blood which is further assumed to be the concentration found in arterial blood. The pHi is calculated by substituting the $\mathrm{PCO}_{2 \text { (saline) }}$ and $\mathrm{HCO}_{3 \text { (arterial) }}^{-}$into a modification of the Henderson-Hasselbalch equation:

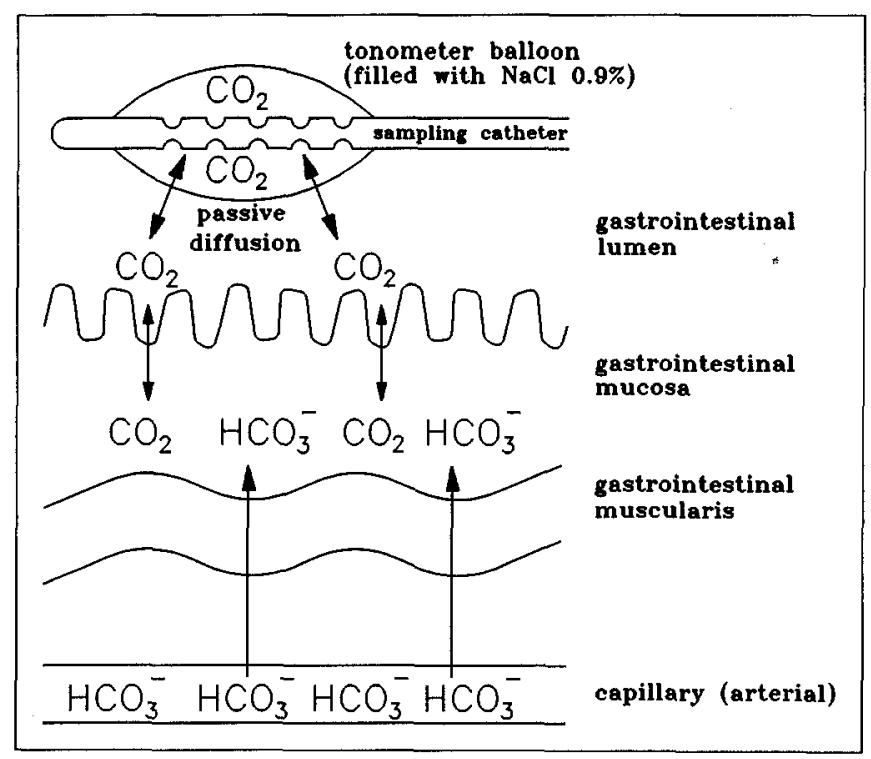

Fig. 1. A schematic representation of a tonometer balloon positioned within the gastrointestinal lumen and the equilibration of partial pressures of $\mathrm{CO}_{2}$

$$
\left.\mathrm{pHi}=6.1 \log \left(\left[\mathrm{HCO}_{3}^{-}\right] / \mathrm{PCO}_{2} \times 0.0307\right]\right)
$$

The tonometer balloon must be refilled with fresh saline and allowed to equilibrate before an additional pHi measurement can be made.

\section{Validity of the technique}

The validity of indirectly measured $\mathrm{pHi}$ was examined by instilling saline directly into the lumen of the stomach $[16,17]$; after an equilibration period, a sample of the solution was withdrawn and its $\mathrm{PCO}_{2}$ determined. In one investigation using dogs, $\mathrm{pHi}$ was measured directly with electrodes implanted in the stomach mucosa and compared to $\mathrm{pHi}$ determined indirectly from gastric (saline) $\mathrm{PCO}_{2}$ and arterial $\mathrm{HCO}_{3}^{-}$concentration (HendersonHasselbalch equation) [11]. Despite some scatter in their data, the authors reported that the direct and indirect $\mathrm{pHi}$ measurements were correlated $(r=0.79)$ although no statistical significance for the correlation coefficient was provided. Coefficients of variation were also calculated for individual dogs and reproducibility for indirectly determined $\mathrm{pHi}$ was $90 \%$ for the pooled results.

In 1984 Fiddian-Green and colleagues proposed modifying the sampling catheter to include a silicone (silastic) balloon to contain the saline [13]. The balloon effectively positioned the saline within a specific location of the gastrointestinal tract whilst also preventing its contamination by stomach or intestinal contents. In their investigation, $\mathrm{pHi}$ was determined by a tonometric balloon surgically positioned in the small intestine of dogs who were subsequently subjected to hypoxia (progressive reduction in the inspired $\mathrm{O}_{2}$ fraction $\left(\mathrm{FIO}_{2}\right)$ to a minimum of $5 \%$ ) and intestinal ischemia (ileal $\dot{\mathrm{DO}}_{2}$ reduced progressively to a minimum of $5 \%$ of baseline with a vascular screw clamp on the superior mesenteric artery). The main finding of this study was that $\mathrm{pHi}$, as measured by tonometry, began to decrease only once $\mathrm{DO}_{2}$ was reduced to approximately $60 \%$ of the normal $\dot{\mathrm{DO}}_{2}$. Antonsson and coworkers performed a similar, yet scientifically more rigorous investigation in 1990 using a pig model [18]. In addition to performing tonometry they also measured $\mathrm{pHi}$ directly with electrodes and found good agreement between the two methods in healthy (normally perfused) pigs. However, in pigs in whom ileal $\mathrm{DO}_{2}$ was totally blocked with a vascular screw clamp on the superior mesenteric artery, tonometrically determined $\mathrm{pHi}$ underestimated the true change in pHi. They suggested that arterial $\mathrm{HCO}_{3}^{-}$concentration overestimated the true ileal mucosal $\mathrm{HCO}_{3}^{-}$; the buffering capacity within the mucosa would have been rapidly utilized as the ischemic intestine was forced to rely more on anaerobic glycolysis. However, during more moderate reductions in ileal $\dot{\mathrm{DO}}_{2}$, tonometrically determined $\mathrm{pHi}$ and electrode $\mathrm{pHi}$ decreased similarly. Lastly, the investigators showed that both the direct and indirect measurements of pHi decreased equally in a group of pigs made septicemic with bacterial endotoxin.

A controversial issue concerning the validity of tonometry is the effect on indirect $\mathrm{pHi}$ measurements of in- 
traluminal $\mathrm{CO}_{2}$ produced when pancreatic $\mathrm{HCO}_{3}^{-}$buffers acid released into the lumen of the stomach. Heard and colleagues examined the effects of $\mathrm{H}_{2}$-receptor blockade on tonometrically determined $\mathrm{pHi}$ in fasted healthy volunteers [19]. These workers demonstrated that $\mathrm{pHi}$ was significantly higher in a group of men given ranitidine compared to a group receiving the placebo (pHi 7.39 vs 7.30 respectively) due to significantly higher $\mathrm{PCO}_{2}$ in the gastric lumen of the placebo group. The main conclusion from the study was that $\mathrm{H}_{2}$-receptor blockade should be used during tonometry to avoid a false reduction of gastric pHi measurements.

Haglund and colleagues have performed many experimental studies using tonometry in pigs and have subsequently reported much basal (healthy) $\mathrm{pHi}$ data from tonometers sited in the stomach, small intestine and sigmoid colon $[20,21]$. In control pigs not given $\mathrm{H}_{2}$-receptor blockers, gastric $\mathrm{pHi}$ (average $\mathrm{pHi}=7.25$ ) was consistently lower than measurements in the intestine (average $\mathrm{pHi}=7.39$ ) and sigmoid colon (average $\mathrm{pHi}=7.36$ ). It may be suggested, however, that back diffusion (titration) of $\mathrm{CO}_{2}$ into the gastric lumen caused an artificial lowering of the gastric pHi measurements.

\section{Clinical applications}

In an early clinical evaluation of indirectly determined $\mathrm{pHi}, 103$ subjects were studied including healthy volunteers and critically ill patients [12]. From amongst a list of variables that included the $\mathrm{pH}$ of arterial blood, gastric juice, and stomach wall ( $\mathrm{pHi}$, indirectly determined), $\mathrm{PCO}_{2}$ and $\mathrm{PO}_{2}$ in arterial blood and gastric juice, and arterial $\left[\mathrm{HCO}_{3}^{-}\right]$it was concluded that $\mathrm{pHi}$ was the best indicator of serious hemorrhage associated with gastric ulceration in patients (i.e. pHi decreased below the normal lower limit, i.e. 7.24, indicates bleeding).

Reports in the literature suggest that $5-15 \%$ of patients undergoing aortic surgery experience ischemic colitis during their post-operative period. While the majority of these patients do not have any further complications, a small number will develop bowel infarction.

One of the first clinical studies using colonic tonometry was performed in 25 patients undergoing elective aortic operations who were considered at risk of developing ischemic colitis [22]. Low pHi measurements in six patients suggested that an ischemic episode had occurred and four of the patients went on to develop symptoms indicative of ischemic colitis. In the 19 patients where $\mathrm{pHi}$ measurements were normal none developed ischemic colitis. The authors concluded that pHi measurement was the best predictor of ischemic colitis following aortic surgery. Another study of tonometry by Fiddian-Green [23] examined patients undergoing cardiac surgery. Measurements of blood pressure, cardiac index, arterial $\mathrm{pH}$, urine production on the day of operation, and $\mathrm{pHi}$ (gastric) were evaluated for their ability to predict complications within the 30 day post-operative period or until death, if the patient died before 30 days. Regression analyis indicated $\mathrm{pHi}$ as the most sensitive (though not the most specific) predictor of post-operative complications.
Correlation coefficients between gastric pHi and indices of hepatic hypoxia including hepatic venous oxygen saturation, hepatic venous $\mathrm{PO}_{2}$, and hepatic venous lactate concentration were calculated in another study of patients undergoing cardiac surgery [24]. Using absolute values of the hepatic hypoxia indices in a regression analysis, gastric pHi was shown to be correlated significantly with hepatic venous $\mathrm{PO}_{2}, \mathrm{O}_{2}$ saturation, lactate concentration and $\mathrm{pH}$. However, as pointed out by Silverman, the analyses would have been improved if changes in the hypoxia indices had been measured over time and then included in a stepwise multiple regression analysis [25]. Furthermore, the authors were criticised for not having demonstrated unequivocally in their patients the presence of hepatic ischemia [25].

Finnish workers recently assessed splanchnic and peripheral perfusion during the hypothermic perioperative and the post-operative periods of 18 patients requiring surgery for ischemic heart disease [26]. Gastric pHi, an indication of visceral perfusion, was compared with measurements of peripheral perfusion including subcutaneous tissue and transcutaneous $\mathrm{PO}_{2}$. The investigators showed that gastric $\mathrm{pHi}$, i.e. visceral perfusion, was better preserved than peripheral perfusion during the early part of the operation and they suggested that peripheral vasoconstriction, in response to the perioperative cooling, helped to maintain visceral perfusion. However, visceral perfusion had also decreased significantly by the end of the surgery and was markedly reduced during the postoperative rewarming period despite data indicating normal central hemodynamics.

A study of 59 surgical patients admitted to an intensive care unit (ICU) showed that $37 \%$ of patients with $\mathrm{pHi}<7.32$ compared to $0 \%$ of patients with a $\mathrm{pHi}$ $\geq 7.32(p<0.01)$ died within $72 \mathrm{~h}$ [27]. Furthermore, 50\% of the deaths occurred in patients with septicemia; in the septic patients a significant $(p<0.01)$ inverse correlation was demonstrated between $\mathrm{pHi}$ and the sepsis score of Elebute and Stoner [28]. However, the authors failed to demonstrate any ability of $\mathrm{pHi}$ measurements to predict long term outcome.

A series of studies using tonometry on intensive care units has been reported recently by Gutierrez and colleagues. In the first of these studies, 80 consecutive patients admitted to that ICU had pHi measured [29]. The mortality was greater in 54 patients with low pHi $(<7.35)$ compared to 26 patients with normal pHi (mortality 65 versus $44 \% ; p<0.05$ ). In another investigation of 22 patients, $\mathrm{pHi}$ was compared with standard measurements of systemic oxygenation for as long as a pulmonary artery catheter was in place [30]. Survivors and nonsurvivors had similar $\dot{\mathrm{DO}}_{2}$ during the investigative period but nonsurvivors had greater $\mathrm{VO}_{2}, \mathrm{O}_{2}$ extraction ratio, and serum lactate concentration than survivors. The authors concluded their report by stating that $\mathrm{pHi}$ measurements were a useful addition to standard methods of assessing systemic oxygenation.

Lastly, results from one large multicentre trial assessing the usefulness of tonometry in predicting those patients likely to experience complications arising from decreased systemic $\mathrm{DO}_{2}$ was reported by Gutierrez and col- 
laborators in 1992 [31]. This investigation went a step further than previous work in that pHi measurements were used to prescribe resuscitative therapy in addition to standard ICU treatment. Surgical and medical patients $(n=260)$ admitted to intensive care units with moderate severity (APACHE II score range between 15-25) had a gastric tonometer placed and their pHi monitored for 5 days or until they were discharged from the ICU. Patients were classified into two groups based on their admission pHi: $\mathrm{pHi} \geq 7.35$ and $\mathrm{pHi}<7.35$. The two groups were each further subdivided into control groups (standard ICU care) and groups receiving extra treatment: in addition to standard ICU care, intravenous fluids and dobutamine were given to increase systemic $\mathrm{DO}_{2}$ and attempt to raise $\mathrm{pHi}$ (a) whenever $\mathrm{pHi}$ fell below 7.35 and (b) for as long as pHi remained below 7.35. All patients received $\mathrm{H}_{2}$-receptor blockers throughout the study. Patients admitted with $\mathrm{pHi}<7.35$ who were subdivided into the control and treatment groups had similar survival rates; tonometrically directed treatment did not significantly influence outcome in these subgroups. However, patients admitted with a normal $\mathrm{pHi}$ but who received extra treatment whenever pHi fell below 7.35 had a significantly higher survival rate than the control group (58 versus $42 \% ; p<0.01)$. It is noteworthy, however, that the mortality in this report, in regard to the APACHE II scores, was higher than expected.

A recently published study by Boyd and colleagues [32] investigated the relationships between conventional blood gas variables and pHi measurements. In 20 consecutive patients admitted to their ICU pHi was significantly correlated with base deficit and excess: (1) in blood $(r=0.63 ; p<0.001)$ and (2) in extracellular fluid $(r=0.60 ; p<0.001)$. Furthermore, blood base deficit and excess consistently decreased in parallel with $\mathrm{pHi}$ in all patients and was thus perceived to be as effective an indicator of splanchnic acidosis as pHi. The authors concluded their report by stating that gastric tonometry provided information to guide treatment that could be obtained more easily from blood gas measurements. However, the absence of a base deficit may not always reflect adequate gut mucosal perfusion.

\section{Summary}

Tonometry is a relatively non-invasive procedure for assessing the intramucosal $\mathrm{pH}$ of the gastrointestinal tract. The technique is based on the assumptions that: (i) the $\mathrm{PCO}_{2}$ in the gastrointestinal lumen is in equilibrium with the $\mathrm{PCO}_{2}$ in the superficial layers of the gut mucosa and (ii) the $\mathrm{HCO}_{3}^{-}$concentration in the mucosal cells is accurately reflected by the $\mathrm{HCO}_{3}^{-}$content of arterial blood. The accuracy of $\mathrm{pHi}$ measurements is reportedly enhanced when $\mathrm{H}_{2}$-receptor blocking agents are used. The cost of the tonometer is substantial, but it seems that tonometry can be incorporated into the routine clinical monitoring procedure of the critically ill patient. Once ICU personnel become competent with the technique it can possibly be used as an early sign of gut ischemia in selected patients predisposed to splanchnic hypoperfu- sion and potentially at risk of developing an infarction of the gastrointestinal tract. However, tonometry appears not to be superior to the measurement of base deficit in blood and has little clinical benefit for those patients in shock who are actively resuscitated. Monitoring $\mathrm{pHi}$ could be of benefit to the patient who is at risk of developing shock and in whom monitoring variables generally obtained by systemic arterial and pulmonary artery (Swan-Ganz) cannulation are not available.

\section{References}

1. Mohsenifar Z, Goldbach P, Tashkin DP, Campisi DJ (1983) Relationship between $\mathrm{O}_{2}$ delivery and $\mathrm{O}_{2}$ consumption in the adult respiratory distress syndrome. Chest 84:267-271

2. Cain SM (1983) Peripheral oxygen uptake and delivery in health and disease. Clin Chest Med 4:139-148

3. Bihari DJ, Gimson AE, Williams R (1986) Cardiovascular, pulmonary and renal complications of fulminant hepatic failure. Semin Liver Dis 6:119 - 128

4. Oshima A, Bulkley GB (1984) Selective reduction of upper gastrointestinal blood flow in cardiogenic shock: mediation via the reninangiotensin axis. Surg Forum 35:169-171

5. Hilton JG, Marullo DS (1987) Trauma induced increase in plasma vasopressin and angiotensin II. LIfe Sci 41:2195-2198

6. Lefer AM (1987) Interaction between myocardial depressant factor and vasoactive mediators with ischemia and shock. Am J Physiol 252:R193-R205

7. Desai MH, Herndon DN, Rutan RL, Abston S, Linares HA (1991) Ischemic intestinal complications in patients with burns. Surg Gynecol Obstet 172:257-261

8. Deitch EA, Berg R (1987) Bacterial translocation from the gut: a mechanism of infection. J Burn Care Rehabil 8:475-482

9. Shoemaker WC, Czer LSC (1979) Evaluation of the biologic importance of various hemodynamic and oxygen transport variables: which variables should be monitored in postoperative shock? Crit Care Med 7:424-431

10. Cohen IL, Lumb PD (1991) Monitoring tissue oxygen perfusion: global or regional? Intensive Crit Care Digest 10:56-59

11. Fiddian-Green RG, Pittenger G, Whitehouse WM (1982) Back diffusion of $\mathrm{CO}_{2}$ and its influence on the intramural $\mathrm{pH}$ in gastric mucosa. J Surg Res 33:39-48

12. Fiddian-Green RG, McGough E, Pittenger G, Rothman ED (1983) Predictive value of intramural $\mathrm{pH}$ and other risk factors for massive bleeding from stress ulceration. Gastroenterology 85:613-620

13. Grum CM, Fiddian-Green RG, Pittenger GL, Grant BJB, Rothman

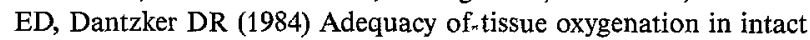
dog intestine. J Appl Physiol 56:1065-1069

14. Fiddian-Green RG (1992) Tonometry: theory and applications. Intensive Care World 9:60-65

15. Fiddian-Green RG (1984) A sensitive and specific diagnostic test for intestinal ischemia using Silastic tonometers. Eur Surg Research $16: 32$

16. Bergofsky EH (1964) Determination of tissue $\mathrm{O}_{2}$ tensions by hollow visceral tonometers: effect of breathing enriched $\mathrm{O}_{2}$ mixtures. J Clin Invest 43:193-200

17. Dawson AM, Trenchard D, Guz A (1965) Small bowel tonometry: assessment of small gut mucosal oxygen tension in dog and man. Nature (London) 206:943-944

18. Antonsson JB, Boyle CC, Kruithoff KL, Wang H, Sacristan E, Rothschild HR, Fink MP (1990) Validation of tonometric measurement of gut intramural $\mathrm{pH}$ during endotoxemia and mesenteric occlusion in pigs. Am J Physiol 259:G519-G523

19. Heard SO, Helsmoortel CM, Kent JC, Shahnarian A, Fink MP (1991) Gastric tonometry in healthy volunteers: effect of ranitidine on calculated intramural pH. Crit Care Med 19:271-274

20. Montgomery A, Hartmann M, Jönsson K, Haglund U (1989) Intramucosal $\mathrm{pH}$ measurement with tonometers for detecting gas- 
trointestinal ischemia in porcine hemorrhagic shock. Circ Shock 29:319-327

21. Hartmann M, Montgomery A, Jönsson K, Haglund U (1991) Tissue oxygenation in hemorrhagic shock measured as transcutaneous oxygen tension, subcutaneous oxygen tension, and gastrointestinal intramucosal pH in pigs. Crit Care Med 19:205-210

22. Fiddian-Green RG, Amelin PM, Herrmann JB, Arous E, Cutler BS, Schiedler M, Wheeler B, Baker S (1986) Prediction of the development of sigmoid ischemia on the day of aortic operations. Arch Surg 121:654-660

23. Fiddian-Green RG, Baker S (1987) Predictive value of the stomach wall $\mathrm{pH}$ for complications after cardiac operations: comparison with other monitoring. Crit Care Med 15:153-156

24. Landow L, Phillips DA, Heard SO, Prevost D, Vandersalm TJ, Fink MP (1991) Gastric tonometry and venous oximetry in cardiac surgery patients. Crit Care Med 19:1226-1233

25. Silverman HJ (1991) Gastric tonometry: an index of splanchnic tissue oxygenation? Crit Care Med 19:1223-1224

26. Niinikoski J, Kuttila K (1993) Adequacy of tissue oxygenation in cardiac surgery: regional measurements (1993) Crit Care Med 21: $\mathrm{S} 77-\mathrm{S} 83$
27. Tobie G, Hubens A, Neels H, Lauwers LF, Peeters R (1988) Prognostic value of gastric intramural $\mathrm{pH}$ in surgical intensive care patients. Crit Care Med 16:1222-1224

28. Elebute EA, Stoner HB (1983) The grading of sepsis. Br J Surg $70: 29-31$

29. Doglio GR, Pusajo JF, Egurrola MA, Bonfigli GC, Parra C, Vetere L, Hernandez MS, Fernandez S, Palizas F, Gutierrez G (1991) Gastric mucosal $\mathrm{pH}$ as a prognostic index of mortality in critically ill patients. Crit Care Med 19:1037-1040

30. Gutierrez G, Bismar H, Dantzker DR, Silva N (1992) Comparison of gastric intramucosal $\mathrm{pH}$ with measures of oxygen transport and consumption in critically ill patients. Crit Care Med 20:451-457

31. Gutierrez G, Palizas F, Doglio G, Wainsztein N, Gallesio A, Pacin J, Dubin A, Schiavi E, Jorge M, Pusajo J, Klein F, San Roman E, Dorfman B, Shottlender J, Giniger R (1992) Gastric intramucosal $\mathrm{pH}$ as a therapeutic index of tissue oxygenation in critically ill patients. Lancet 339:195-199

32. Boyd O, MacKay CJ, Lamb G, Bland JM, Grounds RM, Bennet ED (1993) Comparison of clinical information gained from routine blood-gas analysis and from gastric tonometry for intramural $\mathrm{pH}$. Lancet 341:142-146 